\title{
Epidemiological markers of Salmonella typhimurium isolates in Rome
}

\author{
ANNARITA MARTINI, EMMA FILETICI and MIRELLA FANTASIA* \\ Laboratorio di Batteriologia e Micologia Medica, Istituto Superiore di Sanità, Rome, Italy
}

\begin{abstract}
Summary. The phage type, antimicrobial resistance pattern, colicinogenic activity and DNA plasmid content of 172 strains of Salmonella typhimurium isolated in Rome from 1984 to 1986 were determined; 142 isolates were from patients with enteritis, 30 were from asymptomatic subjects. Most of the phage types identified were isolated during 2 or 3 of the study years; others, e.g., PT141, PT 204c and PT 194 were isolated during 1 year only, and only the last of these was isolated in large numbers. Phage typing proved most valuable in identifying epidemiologically related strains; DNA plasmid analysis was most useful in characterising further cultures of the same phage type, especially those isolated during suspected epidemics.
\end{abstract}

\section{Introduction}

Salmonella typhimurium is currently the commonest salmonella serotype isolated in Italy from both sick and healthy people and animals; ${ }^{1}$ it has also often caused food-poisoning epidemics in Italy ${ }^{2}$ and many other countries. ${ }^{3,4}$ To determine the differences or similarities between isolates, the phage type and antimicrobial resistance pattern of $S$. typhimurium isolates received by the National Enterobacteria Centre at Istituto Superiore di Sanità, Rome, were determined and, because many strains are not sensitive to standard phages, DNA plasmid profiles were also determined. This has been shown to be particularly useful in identifying epidemiologically related isolates. ${ }^{5-7}$ Colicinogenic activity, considered to be important in the establishment of intestinal infections, ${ }^{8,9}$ was also measured and its epidemiological usefulness was examined.

This study compared the characteristics of strains isolated from people in the Rome area to determine whether analysis of plasmid DNA is as valuable an epidemiological marker as phage type or antibiotic resistance pattern.

\section{Materials and methods}

\section{Bacterial strains}

During the 3 years 1984-1986, 172 S. typhimurium strains isolated from people in nine districts of Rome were sent to the National Enterobacteria Centre at the Istituto Superiore di Sanitá, Rome, for serotyping. All

Received 22 March 1990; final amended version accepted 2 Oct. 1991.

* Correspondence should be sent to Dr M. Fantasia. had been isolated from faeces; 142 from patients with enteritis and 30 from asymptomatic subjects. Fortyeight of the former were isolated from patients in the Palestrina Hospital, district number 28, during May $1985 ; 45$ strains were isolated at the Military Hospital in Rome, district number 1, during June and July 1985, 44 of them from patients suffering from enteritis and one from a healthy man; four strains were isolated at the Anzio Hospital, district number 35, between 22 and 27 July 1985, from children aged from 5 months to 8 years suffering from diarrhoea; the isolation of the remaining 75 strains was scattered in time and place.

Antimicrobial susceptibility was determined by a disk-diffusion method ${ }^{10}$ with disks (Baltimore Biological Laboratories, PO Box 243 Cockeysville, MD 21030, USA) containing ampicillin (AM) $10 \mu \mathrm{g}$, cephalothin (CF) $30 \mu \mathrm{g}$, chloramphenicol (C) $30 \mu \mathrm{g}$, colistin (CL) $10 \mu \mathrm{g}$, gentamicin (GM) $10 \mu \mathrm{g}$, kanamycin (K) $30 \mu \mathrm{g}$, streptomycin (S) $10 \mu \mathrm{g}$, sulphisoxazole (ST) $1 \mathrm{mg}$, tetracycline (TE) $30 \mu \mathrm{g}$, tobramycin (TM) $10 \mu \mathrm{g}$, and trimethoprim sulphamethoxazole (SXT) $25 \mu \mathrm{g}$.

Colicinogenic activity. Cultures were examined for colicin production by an overlay method. ${ }^{11}$

Phage typing. The strains were typed by Anderson's method $^{12}$ with 31 type phages; untypable strains were sent for typing to the International Reference Laboratory for Enteric Phage Typing, Central Public Health Laboratory, Colindale Avenue, London.

Plasmid profile analysis. Plasmid DNA was extracted by the method of Kado and $\mathrm{Liu}^{13}$ modified by adding two volumes of $n$-amyl alcohol:chloroform (1:24) solution after adding two volumes of phenol:chloroform (1:1) solution. Crude preparations were analysed by agarose gel electrophoresis ${ }^{14}$ with the following plasmid mol. wt standards: $\mathrm{PBr}$ 322, V 517, RP4, R 144, R27, RA 1. 
Transfer of resistance plasmids was attempted by Datta's method. ${ }^{15}$

Plasmid compatibility groups were determined by the method of Grindley et al. ${ }^{16}$

\section{Results}

Of the $172 \mathrm{~S}$. typhimurium strains isolated in the Rome area (20 in 1984, 112 in 1985 and 40 in 1986), $89.5 \%$ belonged to 20 different phage types (PT). Seven cultures did not conform to a recognised pattern (RDNC) and 12 were not typable (U) with standard typing phages (table I). Of the 20 strains isolated during 1984 (11 from sick and nine from healthy people), 16 belonged to seven different phage types; four were untypable. Of the 112 strains isolated during 1985 (108 from sick and four from healthy people), 107 belonged to 11 different phage types; of these, 45 were PT141, 46 PT194, two were untypable and three were RDNC. Of the 40 strains isolated in 1986 ( 23 from sick and 17 from healthy people), 30 belonged to 17 different phage types, six were untypable and four were RDNC.

Eighty-seven isolates were sensitive to all the antimicrobial agents tested; 59 isolates were resistant to three or more agents.

Fourteen isolates had no plasmids; 17 had one large plasmid each, ranging in size from 47 to $90 \mathrm{mDa}$; two isolates had two plasmids, of 25 and $100 \mathrm{mDa} ; 124$ isolates had both small and large plasmids of 1.34 and $150 \mathrm{mDa}$ and 15 isolates had small plasmids of $1.0-4.55 \mathrm{mDa}$. The phage types, antibiotic resistance and plasmid patterns of the isolates studied are listed in table II. Generally, strains of each phage type were heterogeneous with respect to antibiotic sensitivity and plasmid pattern. In two instances only were strains of the same phage type homogeneous in these respects; 40 of the 46 strains of PT 141 and 43 of the 47 strains of PT 194 showed the same resistance and plasmid patterns.

All 45 strains isolated between 22 June and 2 July 1985 at the Laboratory of the Military Hospital in Rome, district 1, (44 of them from patients with enteritis and one from a healthy subject, all of whom had eaten chicken of the same batch), were of PT 141 and were colicinogenic. All but five isolates were sensitive to all the antimicrobial agents tested; three were resistant to ST and SXT, one to S, ST and SXT, and one to S, ST and TE. These strains were of two different plasmid profiles: all but one had a plasmid of $55 \mathrm{mDa}$ and two small plasmids of 3.5 and $2 \mathrm{mDa}$, respectively; four had a fourth plasmid of $65 \mathrm{mDa}$. A further strain of PT 141 carrying plasmids of 50 and $3.31 \mathrm{mDa}$ was isolated in 1986 in district 35 . Of the strains of PT 141 lacking the $65 \mathrm{mDa}$ plasmid, 40 were sensitive to all the antimicrobial agents tested and one was resistant to $\mathrm{S}$ and SXT. Of four strains harbouring the $65 \mathrm{mDa}$ plasmid, two were resistant to $\mathrm{S}$ and SXT, one to S, ST and SXT, and one to S, ST and TE.
Table I. The most frequent $S$. typhimurium phage types isolated in the Rome area by year

\begin{tabular}{lcccc}
\hline $\begin{array}{l}\text { Phage } \\
\text { type }\end{array}$ & \multicolumn{3}{c}{ Number of isolates in } & $\begin{array}{c}\text { Total } \\
\text { number of } \\
\text { isolates }\end{array}$ \\
\cline { 2 - 4 } & 1984 & 1985 & 1986 & 6 \\
10 & 3 & - & 3 & 11 \\
12 & 7 & - & 4 & 46 \\
141 & - & 45 & 1 & 4 \\
170 & 1 & 1 & 2 & 47 \\
194 & 2 & 46 & 1 & 7 \\
195 & 1 & 2 & 3 & 8 \\
U285 & - & 4 & 3 & 4 \\
$204 c$ & - & 3 & 4 & 7 \\
RDNC & 4 & 2 & 6 & 12 \\
U & 2 & 5 & 13 & 20 \\
Others (12) & 20 & 112 & 40 & 172 \\
Total & & & & \\
\hline
\end{tabular}

RDNC, cultures did not conform to a recognised pattern. $\mathrm{U}$, untypable.

Forty-five strains of PT 194 were isolated during May 1985 at the laboratory of the Palestrina Hospital, district 28, from patients with enteritis, all of whom shortly before admission had eaten pork at a wedding dinner at the same restaurant. Unfortunately, no isolates from the pork were available for characterisation, but all 45 strains showed the same plasmid profile: two large plasmids of 65 and $55 \mathrm{mDa}$ and five small plasmids of $3 \cdot 9,3 \cdot 1,2 \cdot 4,2$ and $1 \cdot 7 \mathrm{mDa}$. The 65 $\mathrm{mDa}$ plasmid was autotransferable. Forty-three of these isolates were resistant to S, ST, SXT and TE, one was resistant to CF, CL, S, ST, SXT and TE, and one to S, ST and SXT; only this last was colicinogenic. From further subjects attending the same wedding dinner and who had also eaten pork, a PT 193 culture resistant to TE and two untypable cultures of $S$. typhimurium resistant to $\mathrm{CF}, \mathrm{ST}$ and TE were isolated; they carried plasmids differing in number and weight from those of PT 194 strains. Two further cultures of PT 194 were isolated in two different districts of Rome. One, isolated in 1985, was resistant to AM, S and ST and carried plasmids of $52,1.8$ and $1.6 \mathrm{mDa}$, and one isolated in 1986 was resistant to $\mathrm{Te}$ and carried plasmids of 75 and $52 \mathrm{mDa}$.

Four strains of PT 204c were isolated between 22 and 27 July 1985 in the laboratory of Anzio Hospital, district 35 , from children aged 5 months to 8 years suffering from diarrhoea. All produced colicins and all showed the same antibiotic resistance pattern. These strains carried three plasmids of 150,60 and $30 \mathrm{mDa}$ respectively; three of them carried a small plasmid of $3.5 \mathrm{mDa}$; the fourth had a small plasmid of $2.5 \mathrm{mDa}$. The three larger plasmids were autotransferable: the largest, of $150 \mathrm{mDa}$ and of compatibility group $\mathrm{H}$, coded for resistance to C, S, ST, SXT and TE; the plasmid of $60 \mathrm{mDa}$, of compatibility group I $\alpha$ coded for resistance to $\mathrm{Gm}, \mathrm{S}$ and $\mathrm{TM}$ and for colicin production. 
Table II. S. typhimurium strains isolated in the Rome area characterised by phage type, antibiotic-resistance pattern and DNA plasmid profile

\begin{tabular}{|c|c|c|}
\hline $\begin{array}{l}\text { Phage type } \\
\text { (number of } \\
\text { isolates) }\end{array}$ & $\begin{array}{l}\text { Resistance } \\
\text { pattern } \\
\text { (number of } \\
\text { isolates) }\end{array}$ & $\begin{array}{l}\text { DNA Plasmid size } \\
\text { in mDa } \\
\text { (number of isolates) }\end{array}$ \\
\hline PT 8 (3) & sens (3) & $\begin{array}{l}50(2) \\
1.94(1)\end{array}$ \\
\hline PT $10(6)$ & $\begin{array}{l}\text { AM S ST TE (1) } \\
\text { AM S ST TE (1) } \\
\text { sens (4) }\end{array}$ & $\begin{array}{l}80,24,4 \cdot 5,3 \cdot 3 \\
1.73 \\
-(2) \\
1.62(1) \\
2.04(1)\end{array}$ \\
\hline PT 12 (11) & sens $(8)$ & $\begin{array}{l}50,5(2) \\
50(2) \\
50,3 \cdot 95,2 \cdot 57,1 \cdot 9(1) \\
60(1) \\
60,40(1) \\
4 \cdot 55,2 \cdot 57(1) \\
50,5(2) \\
50,3 \cdot 95,2 \cdot 57,1 \cdot 9(1)\end{array}$ \\
\hline $\begin{array}{l}\text { PT 15a (1) } \\
\text { PT } 29(2)\end{array}$ & $\begin{array}{l}\text { sens } \\
\text { TE (1) } \\
\text { TE (1) }\end{array}$ & $\begin{array}{l}50,2 \cdot 69 \\
50,5 \\
45,3 \cdot 01\end{array}$ \\
\hline $\begin{array}{l}\text { PT } 36(1) \\
\text { PT } 49 b(1) \\
\text { PT } 109(1) \\
\text { PT } 121(1)\end{array}$ & $\begin{array}{l}\text { sens } \\
\text { sens } \\
\text { sens } \\
\text { sens }\end{array}$ & $\begin{array}{l}50,3 \cdot 31 \\
\overline{47} \\
45,2 \cdot 8,1 \cdot 6\end{array}$ \\
\hline PT 135 (3) & $\begin{array}{l}\text { sens (1) } \\
\text { S ST TE (1) } \\
\text { C S ST SXT TE (1) }\end{array}$ & $\begin{array}{l}50,25 \\
50 \\
72,57,33,22 \cdot 4,1 \cdot 34\end{array}$ \\
\hline PT $141(46)$ & $\begin{array}{l}\text { sens (41) } \\
\text { ST SXT (3) } \\
\text { S ST SXT (1) } \\
\text { S ST TE (1) }\end{array}$ & $\begin{array}{l}55,3 \cdot 5,2(40) \\
50,3 \cdot 31(1) \\
55,3 \cdot 5,2(1) \\
65,55,3 \cdot 5,2(2) \\
65,55,3 \cdot 5,2 \\
65,55,3 \cdot 5,2\end{array}$ \\
\hline $\begin{array}{l}\text { PT } 160(2) \\
\text { PT } 170(4)\end{array}$ & $\begin{array}{l}\text { sens } \\
\text { sens (1) } \\
\text { SXT (1) } \\
\text { S SXT (1) }\end{array}$ & $\frac{52}{24,3 \cdot 0}$ \\
\hline & ST SXT (1) & - \\
\hline $\begin{array}{l}\text { PT } 171(1) \\
\text { PT } 178(1)\end{array}$ & $\begin{array}{l}\text { sens } \\
\text { sens }\end{array}$ & $\begin{array}{l}1 \cdot 77,1.44 \\
50\end{array}$ \\
\hline PT 193 (3) & $\begin{array}{l}\text { TE (1) } \\
\text { TE (1) } \\
\text { S (1) }\end{array}$ & $\begin{array}{l}55,4 \cdot 7,3 \cdot 7,3,2 \cdot 2,1 \cdot 8 \\
60 \\
52\end{array}$ \\
\hline PT 194 (47) & $\begin{array}{l}\text { TE (1) } \\
\text { Am S ST (1) } \\
\text { S ST SXT (1) } \\
\text { CF CL S ST SXT TE (1) } \\
\text { S ST SXT TE (43) }\end{array}$ & $\begin{array}{l}75,52 \\
52,1 \cdot 8,1 \cdot 6 \\
65,55,3 \cdot 9,3 \cdot 1,2 \cdot 4,2,1 \cdot 7 \\
65,55,3 \cdot 9,3 \cdot 1,2 \cdot 4,2,1 \cdot 7 \\
65,55,3 \cdot 9,3 \cdot 1,2 \cdot 4,2,1 \cdot 7\end{array}$ \\
\hline PT 195 (7) & $\mathrm{TE}(7)$ & $\begin{array}{l}36,4 \cdot 36,4 \cdot 07,3 \cdot 31,2 \cdot 95,2 \cdot 57,2 \cdot 04(1) \\
50(1) \\
60(1) \\
50,3 \cdot 95,2 \cdot 57,1 \cdot 9(1) \\
45,5 \cdot 49,2 \cdot 8,1 \cdot 6(1) \\
90(1) \\
54,5(1)\end{array}$ \\
\hline U285 (8) & sens $(8)$ & $\begin{array}{l}-(3) \\
1 \cdot 54,1 \cdot 2(2) \\
1 \cdot 54(2) \\
4 \cdot 36,3 \cdot 0,1 \cdot 54(1)\end{array}$ \\
\hline $204 c(4)$ & $\begin{array}{l}\text { AM C GM K NA S ST } \\
\text { SXT TE TM (4) }\end{array}$ & $\begin{array}{l}150,60,30,2 \cdot 5(1) \\
150,60,30,3 \cdot 5(3)\end{array}$ \\
\hline RDNC (7) & sens $(6)$ & $\begin{array}{l}-(4) \\
1.0(1) \\
3.95,2.57(1)\end{array}$ \\
\hline $\mathrm{U}(12)$ & $\begin{array}{l}\text { K S ST TE (1) } \\
\text { sens (6) }\end{array}$ & $\begin{array}{l}1.34 \\
-(1) \\
50(1) \\
52(1) \\
45,2 \cdot 08(1) \\
60,3.95,2.57(1) \\
3 \cdot 71,2 \cdot 23,1.90(1)\end{array}$ \\
\hline & TE (2) & $\begin{array}{l}50,5(1) \\
20,4 \cdot 07,3 \cdot 09,2.04(1)\end{array}$ \\
\hline & $\begin{array}{l}\text { ST (1) } \\
\text { S ST (1) } \\
\text { CF ST TE (2) }\end{array}$ & $\begin{array}{l}60,3 \cdot 95,2 \cdot 57 \\
60 \\
100,25\end{array}$ \\
\hline
\end{tabular}

RDNC, cultures did not conform to recognised pattern.

$\mathrm{U}$, untypable. 


\section{Discussion}

Twenty different phage types of S. typhimurium were represented among 172 strains isolated in Rome during the 3 years 1984-1986. Three phage types were prominent. Firstly, four multi-resistant strains of PT $204 \mathrm{c}$ were isolated from children with diarrhoea in district 35 during July 1985. Although PT 204c strains have been isolated in the UK with increasing frequency from both man and animals ${ }^{17}$ they have not until now been recognised in Italy as a cause of human gastroenteritis. All four isolates were resistant to gentamicin, as described by Threlfall et al ${ }^{18,19}$ for strains isolated from cattle and man and the plasmid profile also resembles that described by Threlfall et al. ${ }^{20}$ for strains isolated in the UK. A plasmid of compatibility group $\mathrm{H}$, conferring resistance to $\mathrm{C}, \mathrm{S}, \mathrm{ST}, \mathrm{SXT}$ and $\mathrm{TE}$, and a plasmid of compatibility group $\mathrm{X}$, conferring resistance to $A M$ and $K$, were present. The plasmid responsible for resistance to GM, S and TM belonged to compatibility group I $\alpha$ and, unlike plasmids of strains isolated from people studied by Threlfall et al. ${ }^{20}$ it also specified colicinogeny. Except for the small plasmids, the four strains had similar characteristics; unfortunately, although all were isolated in the same month the circumstances in which they were found were not investigated epidemiologically. Multi-resistant strains of S. typhimurium PT $204 \mathrm{c}$ circulate among cattle in Europe: $:^{19}$ in Italy, multi-resistant strains of PT 204 and 204a have been isolated from cattle ${ }^{21}$ and, recently, gentamicin-resistant isolates from cattle in Italy showed a phage lysis pattern resembling that of PT 204c and harboured plasmids with the same electrophoretic motility as those found in strains from man. Only three of the PT $204 \mathrm{c}$ strains produced colicins.

Secondly, of 46 PT 141 isolates, 45 were isolated during 2 consecutive months from patients in the Military Hospital, Rome, and probably represent a point-source outbreak of food-poisoning from chicken although none was available for bacteriological examination. Salmonellae colonise poultry easily and this forms a major worldwide source of salmonellosis. ${ }^{17}$ Strains of PT 141 are often isolated from poultry; ${ }^{22,23}$ two have been isolated from chicken in Northern Italy. Such strains are usually fully sensitive to antibiotics and often cause food poisoning. ${ }^{23-25}$ of the 45 epidemiologically related strains of PT 141, all were colicinogenic $; 0$ were sensitive to all the antimicrobial agents tested and all carried the same plasmids. These strains were isolated early in the outbreak; the remaining PT 141 strain was isolated later, had a different plasmid profile and was antibiotic resistant. A $55-\mathrm{mDa}$ plasmid also present in the antibioticsensitive strains has been described as specifying virulence characteristics. ${ }^{26,27}$

Forty-five strains of PT 194 were isolated from patients in district 28 during May, 1985. This phage type, while not frequent in the UK nor in Spain, Portugal or Greece, was so often isolated from pigs in Belgium and from people in France and Germany as to constitute a widespread clonal outbreak. ${ }^{28}$ Fortythree of the 45 PT 194 strains did not produce colicins were resistant to S, ST, SXT and TE, and had the same plasmid profile. The remaining two strains had the same plasmid profile, produced colicins, but differed from the former strains and from each other in their antibiotic-resistance patterns. Such variations among strains of the same phage type have been noted ${ }^{6}$ the possibility that the strains belong to the same clone cannot be ruled out.

These results confirm that not all salmonella strains isolated from epidemiologically related patients belong to the same phage type and show that, among those that do, secondary tests for antibiotic sensitivity, colicin production and plasmid content are of limited value in determining epidemiologically related subsets.

We thank Dr B. Rowe and his colleagues for phage typing $S$. typhimurium strains.

\section{References}

1. Fantasia M, Filetici E, Mondello F, Vergati A. Osservazioni su stipiti di Salmonella esaminati presso l'Istituto Superiore di Sanità negli anni 1980-1983. Distribuzione di sierotipi e sensibilità agli antimicrobici. Rapporti Istisan 1984; $84 / 24$.

2. Fantasia M, Filetici E. Serotypes of Salmonella spp. isolated from man and foods in Italy from 1973 to 1983 . Igiene Moderna 1986; 85: 489-497.

3. PHLS Communicable Diseases Surveillance Centre. Food poisoning and salmonella surveillance in England and Wales: 1983. $B M J 1985 ; 291$ : 394-396.

4. Centers for Disease Control. 1983. Foodborne disease outbreaks. Annual Summary 1981

5. Farrar WE Molecular analysis of plasmids in epidemiologic investigation. J Infect Dis 1983; 148: 1-6.

6. Holmberg SD, Wachsmuth IK, Hickman-Brenner FW, Cohen ML. Comparison of plasmid profile analysis, phage typing, and antimicrobial susceptibility testing in characterizing Salmonella typhimurium isolates from outbreaks. J Clin Microbiol 1984; 19: 100-104.

7. Taylor DN, Wachsmuth IK, Shangkuan Y et al. Salmonellosis

associated with marihuana. $N$ Engl $J$ Med 1982; 309: 1249-1253.

8. Sharma PL, Sharma KB, Prakash K. Colicin production and coexistence of $\mathrm{Col}^{+}$plasmid with R-plasmid in salmonellae. Indian J Med Res 1984; 79, 591-593.

9. Vicente ACP, de Almeida DF. Identification of multipleresistance (R) and colicinogeny (Col) plasmids in an epidemic Salmonella agona serotype in Rio de Janeiro. $J$ Hyg 1984; 93: 79-84.

10. Bauer AW, Kirby WMM, Sherris JC, Turck M. Antibiotic susceptibility testing by a standardized single disk method. Am J Clin Pathol 1966; 45: 493-497.

11. Fredericq P. Colicins. Annu Rev Microbiol 1957; 11: 7-22.

12. Anderson ES, Williams REO. Bacteriophage typing of enteric pathogens and staphylococci and its use in epidemiology. $J$ Clin Pathol 1956; 9: 94-115.

13. Kado CI, Liu S-T. Rapid procedures for detection and isolation of large and small plasmids. $J$ Bacteriol 1981; 145: 1365-1373.

14. Meyers JA, Sanchez D, Elwell LP, Falkow S. Simple agarose gel electrophoretic method for the identification and characterization of plasmid deoxyribonucleic acid. $J$ Bacteriol 1976; 127: 1529-1537. 
15. Datta $N$. Transmissible drug resistance in an epidemic strain of S. typhimurium. J Hyg 1962; 60: 301-310.

16. Grindley NDF, Grindley JN, Anderson ES. R factor compatibility groups. Mol Gen Genet 1972; 119: 287-297.

17. PHLS Communicable Diseases Surveillance Centre. Food poisoning and salmonella surveillance in England and Wales: 1982. B M J 1984; 288: 306-308.

18. Threlfall EJ, Rowe B, Fergusson JL, Ward LR. Gentamicin resistant Salmonella typhimurium. Vet Rec 1983;113: 627.

19. Threlfall EJ, Rowe B, Ferguson JL, Ward LR. Increasing incidence of resistance to gentamicin and related aminoglycosides in Salmonella typhimurium phage type 204c in England, Wales and Scotland. Vet Rec 1985; 117: 355-357.

20. Threlfall EJ, Ward LR, Rowe B. R plasmids in Salmonella typhimurium in the United Kingdom. $J$ Antimicrob Chemother 1986; 18 Suppl C: 175-177.

21. Falbo V, Caprioli A. Plasmidi di resistanze in stipiti multiresistenti di Salmonella typhimurium di origine bovina e umana. Giornale di Malattie Infettive e Parassitarie. 1983; 35: $884-887$.

22. Coloe PJ, Taplin J, Fromm W. The distribution of specific phage types of Salmonella typhimurium in chickens in Australia. J Hyg 1984; 92 : 177-182.
23. Barker R, Old DC. Biotyping and colicine typing of Salmonella typhimurium strains of phage type 141 isolated in Scotland. J Med Microbiol 1979; 12: 265-276.

24. PHLS Communicable Diseases Surveillance Centre. Salmonella typhimurium phage type 141 infections in Sheffield during 1984 and 1985. Communicable Disease Report 1985; $87 / 15: 3-4$.

25. PHLS Communicable Diseases Surveillance Centre. Gastrointestinal infections, surveillance of food poisoning and salmonellosis. Communicable Disease Report, 1986; 86/44:5.

26. Jones GW, Rabert DK, Svinarich DM, Whitfield HJ. Association of adhesive, invasive, and virulent phenotypes of Salmonella typhimurium with autonomous 60-Megadalton plasmids. Infect Immun 1982; 38: 476-486.

27. Helmuth R, Stephan R, Bunge C, Hoog B, Steinbeck A, Bulling E. Epidemiology of virulence-associated plasmids and outer membrane protein patterns within seven common Salmonella serotypes. Infect Immun 1985; 48: 175-182.

28. Anderson ES. The geographical predominance of resistance transfer systems of various compatibility groups in Salmonellae. Topics in Infectious Disease 1977; 2: 25-41. 